\title{
Changing landscape of nutrition and dietetics research? A bibliographic analysis of top-tier published research in 1998 and 2018
}

\author{
Sze Lin Yoong 1,2,3,*, Jacklyn Jackson 2,3,4, Courtney Barnes 2,3,4,5, Nicole Pearson 2,3,4,5, \\ Taren Swindle 6 , Sharleen $O^{\prime}$ Reilly$^{7}$, Rachel Tabak ${ }^{8}$, Regina Belski ${ }^{1}$, Alison Brown ${ }^{2,3,4,5}$ (i) \\ and Rachel Sutherland $2,3,4,5$ \\ 'Swinburne University of Technology, School of Health Sciences, Hawthorn, VIC 3122 , Australia: ${ }^{2}$ School of Medicine \\ and Public Health, University of Newcastle Callaghan, Newcastle, NSW, Australia: ${ }^{3}$ Hunter Medical Research \\ Institute, Newcastle, NSW, Australia: ${ }^{4}$ Priority Research Centre for Health Behaviour, University of Newcastle, \\ Callaghan, NSW, Australia: ${ }^{5}$ Hunter New England Population Health, Wallsend, NSW, Australia: ${ }^{6}$ Department of

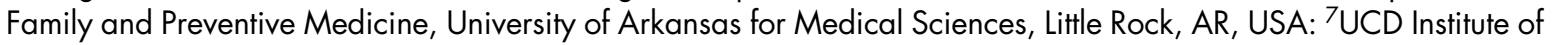 \\ Food and Health, School of Agriculture and Food Science, University College Dublin, Belfield, Ireland: \\ ${ }^{8}$ Prevention Research Center in St. Louis, Brown School, Washington University in St. Louis, St. Louis, MO, USA
}

Submitted 10 August 2020: Final revision received 9 December 2020: Accepted 5 January 2021: First published online 13 January 2021

\begin{abstract}
Objective: The current study sought to describe and compare study type, research design and translation phase of published research in nutrition and dietetic journals in 1998 and 2018.

Design: This was a repeat cross-sectional bibliographic analysis of Nutrition and Dietetics research. All eligible studies in the top eight Nutrition and Dietetics indexed journals in 1998 and 2018 were included. Two independent reviewers coded each study for research design (study type and study design) and translation phase (T0-T4) of the research using seminal texts in the field.

Setting: Not relevant.

Participants: Not relevant.

Results: The number of publications (1998, $n$ 1030; 2018, $n$ 1016) has not changed over time, but the research type, design and translation phases have. The proportion of intervention studies in 1998 (43.8\%) was significantly higher than 2018 (19.4\%). In 2018, more reviews (46.9\% v. $15.6 \%$ in 1998) and less randomised trials (14.3\% $v .37 \cdot 8 \%$ in 1998) were published. In regard to translation phase, there was a higher proportion of T2-T4 research in 2018 (18.3\% v. 3.8 \% in 1998); however, the proportion of $\mathrm{T} 3 / \mathrm{T} 4$ (dissemination, implementation and populationlevel research) research was still low $(<3 \%)$. Our sensitivity analysis with the four journals that remained in the top eight journal across the two time periods found no differences in the research type, design and translation phases across time.

Conclusions: There was a reduction in intervention and T0 publications, alongside higher publication of clinical study designs over time; however, published T3/T4 research in Nutrition and Dietetics is low. A greater focus on publishing interventions and dissemination and implementation may be needed.
\end{abstract}

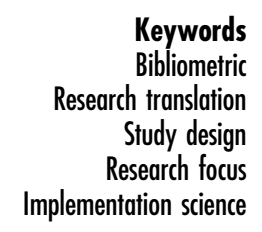

Keywords

Bibliometic

Study design

Research focus

Implementation science
Dietary risk factors such as low intakes of fruits, vegetables and wholegrains, as well as excessive intakes of processed foods, contribute to high intakes of $\mathrm{Na}$, fat and added sug$\operatorname{ars}^{(1)}$. These dietary factors are the primary cause of death and disability for high-income countries globally ${ }^{(1,2)}$. As such, there is a large volume of research and specialist Nutrition and Dietetics journals focused on exploring methods for reducing disease burden related to dietary risk factors, ranging from basic science to the evaluation of public health policies in the community ${ }^{(3,4)}$.

In well-developed research areas including Nutrition and Dietetics, public health experts have proposed that research focus should progress over time, such that findings are increasingly policy and practice relevant to 
facilitate translation into practice. Frameworks such as the Public Sequential Model proposed by Nutbeam in $1996^{(5)}$ and Flay's Eight Phase of Research provide a way of conceptualising this progression ${ }^{(6,7)}$. Both Nutbeam and Flay's models suggest that, over time, there should be progression from research efforts to firstly understand the problem, to testing for efficacy, followed by replicability and ultimately dissemination ${ }^{(6-8)}$. This progression is similar to that described in the United States (US) National Institute of Health and Institute of Medicine, which describes five stages of research translation ranging from T0 to T4 ${ }^{(9-11)}$. Although the scientific community recognises that research translation does not happen in a linear manner ${ }^{(12)}$, these models provide a useful way to describe research type and its relevance to public health practice.

Bibliometric studies, where data are gathered from published sources ${ }^{(13)}$, allow the characterisation of publications within a field, to describe research activity and assess progression. Such analyses have been used to critically examine the progression of research in many fields including Indigenous and rural health ${ }^{(14)}$, physical activity ${ }^{(8)}$, falls prevention $^{(15)}$, as well as smoking ${ }^{(16)}$ and public health ${ }^{(17)}$. These studies have reported a lack of progression of research focus over time, with the overwhelming majority of studies being descriptive and focused on the earlier translation phases. For example, in physical activity research, there was little change in the proportion of descriptive research in the 20-year period between 1988-1989 and 2008-2009 ${ }^{(8)}$. The majority of intervention studies in both time periods were efficacy focused relative to later stages of research translation ${ }^{(8)}$.

To the authors' knowledge, an analysis of the progression of Nutrition and Dietetics research has not been conducted previously. This examination can provide an overview of the changes in publishing priorities and research foci and allows the identification of gaps in production of research evidence. Therefore, the primary aim of the current study was to describe the volume, research design and research translation phase of manuscripts published within the top eight ranked journals in the discipline of Nutrition and Dietetics and compare this across two time periods (1998 and 2018). Additionally, we also sought to assess these changes by journal focus (those that focused on a particular content area (i.e., lipids, obesity) $v$. Those that had a broader nutrition focus, and those with a public health focus as part of their scope $v$. Those that did not have public health as an area of focus).

\section{Methods}

\section{Study design and sample}

A repeat cross-sectional bibliographic study of research published in the top eight ranked Nutrition and Dietetics indexed journals was undertaken for 1998 and 2018. A bibliometric study, where the number and types of published literature are tabulated, enables the description of overall research activity and characterisation of the type of research undertaken in a particular field ${ }^{(18)}$. Firstly, we sampled published research articles from the top eight ranked Nutrition and Dietetics journals, as classified by Web of Science, InCites Journal Citation Reports ${ }^{(19)}$, which are based on journal impact factor. As the impact factor is determined by average citation in the past 2 years, this sampling approach offers an insight into the research priorities of the field ${ }^{(20)}$. Nutrition and Dietetics journals cover a broad range of topics including general nutrition, nutrition and metabolism, nutrition science, clinical nutrition, nutritional biochemistry and resources related to dietetics, which covers the application of nutritional principles (see Table 1). Four of the eight journals were the same across both time points. All title and abstracts of articles from the eight journals published in 1998 and 2018 were downloaded. Four authors (J.J., N.P., A.B. and C.B.) undertook an initial screen using title and abstracts, where studies were included if they were published in English, presented new data (e.g., not editorials, letters without new data) and were not conference abstracts (see Fig. 1 for flow diagram outlining study selection process). This was confirmed in the full-text screen prior to data extraction.

\section{Data extraction}

All studies that met the above criteria were downloaded as full-text articles from e-Journal databases in August 2019. Four authors (J.J., N.P., A.B. and C.B.) independently extracted data using a standardised data extraction form. All data extractors were provided with a list of definitions (see online supplementary material, Supplemental Table S1-S5) and met prior to extraction to calibrate the data extraction processes. An additional reviewer conducted data extraction as a second reviewer for a portion (20\%) of the included studies to check data extraction (S.L.Y.). Differences were resolved via consensus or a third reviewer was consulted (S.L.Y.).

\section{Measures}

Studies were classified as descriptive/epidemiology, measurement or intervention using previous definitions of such research ${ }^{(8,21)}$ (see online supplementary material, Supplemental Table S1). Seminal methodological texts ${ }^{(22-24)}$ were used to classify the research design of included studies (see online supplementary material, Supplemental Table S2 and Table 2). The translational research phase was determined based on the National Institute of Health endorsed criteria (see online supplementary material, Supplemental Table S3) ${ }^{(11)}$. The research translational process was also defined using the Integrative Framework of Dissemination, Implementation and Translation criteria defined by Leppin and colleagues (see online supplementary material, 
Table 1 Top eight ranked journals indexed as Nutrition and Dietetics in 1998 and 2018

\begin{tabular}{|c|c|c|c|c|c|}
\hline \multirow[b]{2}{*}{ Journal } & \multirow[b]{2}{*}{ Scope } & \multicolumn{2}{|l|}{1998} & \multicolumn{2}{|l|}{2018} \\
\hline & & Volume and issues (IF) & $n$ & Volume and issues (IF) & $n$ \\
\hline Progress in Lipid Research & $\begin{array}{l}\text { Lipid biochemistry, chemistry, } \\
\text { biotechnology, industry and } \\
\text { medicine }\end{array}$ & $\begin{array}{l}\text { Vol. } 37 \\
\text { Issues: } 1-6 \\
\text { (IF: } 6 \cdot 0)\end{array}$ & 14 & $\begin{array}{l}\text { Vol. 69-72 } \\
\text { (IF: 12.54) }\end{array}$ & 18 \\
\hline Annual Review of Nutrition & $\begin{array}{l}\text { Energy metabolism, macronutrients, } \\
\text { micronutrients, biochemistry, } \\
\text { nutritional genomics, molecular and }\end{array}$ & $\begin{array}{l}\text { Vol. } 18 \\
\text { (IF: } 5 \cdot 13 \text { ) }\end{array}$ & 18 & $\begin{array}{l}\text { Vol. } 38 \\
\text { (IF: 8.422) }\end{array}$ & 18 \\
\hline
\end{tabular}

American Journal of Clinical Nutrition

Critical Reviews in Food Science and Nutrition

International Journal of Obesity

Lipids

Obesity Research

Journal of Nutrition

Advances in Nutrition

Clinical Nutrition

International Journal of Behavioural Nutrition and Physical Activity

Nutrition Reviews nutritional genomics, molecular and cell biology, clinical nutrition, comparative nutrition, nutritional anthropology, nutritional toxicology, nutritional microbiology, epidemiology and public health nutrition

Primary research journal. Publishes the latest research on topics in nutrition, such as obesity, vitamins and minerals, nutrition and disease and energy metabolism

Current technology, food science and human nutrition. Also, the application of scientific discoveries and the acquisition of knowledge related to nutrition, functional foods, food safety, and food science and technology

Biochemical, physiological, genetic, molecular, metabolic, nutritional, psychological and epidemiological aspects of obesity and related disorders

General area of lipid research, including chemistry, biochemistry, clinical nutrition and metabolism

Research intends to increase knowledge, stimulate research and promote better management of people with obesity

Experimental nutrition in humans and other animal species and controversial issues in nutrition

Nutrition-related research efforts directed towards biochemical, molecular and genetic studies utilising experimental animal models, domestic animals and human subjects. Includes, clinical nutrition, epidemiology, public health and nutritional education

Nutritional and metabolic care, and the relationship between nutrition and disease both in the setting of basic science and clinical practice

Devoted to understanding behavioural aspects of diet and physical activity. Includes multiple levels of analysis, including populations, groups and individuals. Includes epidemiology and behavioural, theoretical and measurement research areas

Authoritative and critical literature reviews on current and emerging topics in nutrition science, food science, clinical nutrition and nutrition policy
Vol. 68

Issues: 1-6

Supp Issues: S2, S4, S6

(IF: 3.417)

Vol. 38

Issues: 1-8

(IF: 2.167)

Vol. 22

Issues: 1-12

(IF: 3.003)

Vol. 33

Issues: 1-12

(IF: 2.364)

Vol. 6

Issues: 1-6

Supp Issue: $\mathrm{S} 1$

(IF: 2.265)

Vol.128

Issue: 1-12

Supp Issue: S2, S12

(IF: 2.127)

Not in top 8 in 1998

Not in top 8 in 1998

Not in top 8 in 1998

Not in top 8 in 1998
194 Vol. 107 and 108

Issues: 1-6
(IF: 6.568)

20 Vol. 58

Issues: 1-18

(IF: 6.704)

175 Not in top 8 in 2018

148 Not in top 8 in 2018

60 Not in top 8 in 2018

401 Not in top 8 in 2018

Vol. 9

Issue 1-6

Supp Issue: S1, S4

(IF: 7.24)

Vol. 37

Issue: $1-5,6 a, 6 B$

(IF: 6.402)

Vol. 15

Issue 1

(IF: 6.037)

Vol. 76

Issue: 1-12

Supp Issue: S1

(IF: 5.779)
65

5

IF, impact factor; Vol., journal volume; Supp Issues, supplementary issues. 


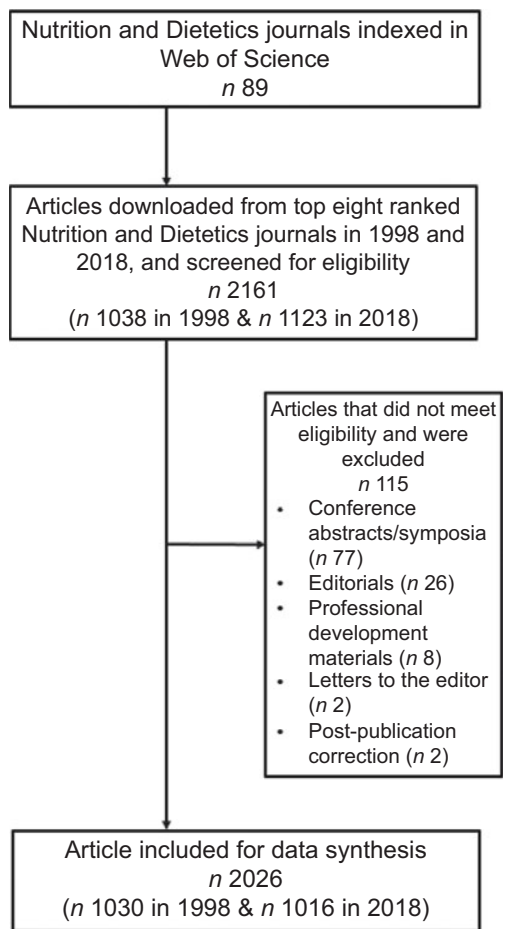

Fig. 1 Flow diagram of study selection process for inclusion
Supplemental Table S4) ${ }^{(25)}$. If studies were classified as implementation and dissemination research (T3 or T4), the researchers examined whether the manuscript included information regarding dissemination ${ }^{(11,26)}$, implementation ${ }^{(26)}$, adaptability $^{(27)}$, sustainability ${ }^{(28)}$ and scaling-up ${ }^{(29)}$ (see online supplementary material, Supplemental Table S5).

\section{Statistical analysis}

Analyses were conducted using STATA 14.2 (StatCorp.). The proportion of publications that were classified under each study type and research design was reported, together with $95 \%$ CI. Pearson's $\chi^{2}$ tests or Fisher's exact where values were $<5$ were undertaken to compare the differences in proportion of studies between 1998 and 2018 as appropriate. Statistical tests were two-tailed with an $\alpha$ of 0.05 . Further, as there were differences in the type and scope of articles included in 1998 and 2018, we undertook a number of subgroup analyses by journal scope (focused on a specific content area (including obesity and lipids, $n 4$ journals) $v$. Nutrition more broadly ( $n 8$ journals), and by those that included public health/ behavioural nutrition ( $n 4$ journals) as a focus and those that did not ( $n 8$ journals)). Additionally, we undertook a sensitivity analysis to examine the trends in the four

Table 2 Study type, design and translational research phase for studies published in the top eight ranked Nutrition and Dietetics journals in 1998 and 2018

\begin{tabular}{|c|c|c|c|c|c|c|c|}
\hline & \multicolumn{3}{|c|}{$1998(n$ 1030) } & \multicolumn{3}{|c|}{$2018(n$ 1016) } & \multirow[b]{2}{*}{$P^{\star}$} \\
\hline & $n$ & Proportion & $95 \% \mathrm{Cl}$ & $n$ & Proportion & $95 \% \mathrm{Cl}$ & \\
\hline \multicolumn{8}{|l|}{ Study type } \\
\hline Descriptive† & 530 & $51 \cdot 4$ & $48 \cdot 4,54 \cdot 5$ & 764 & $75 \cdot 2$ & $72 \cdot 4,77 \cdot 8$ & $<0.001$ \\
\hline Measurement & 49 & $4 \cdot 8$ & $3.5,6 \cdot 2$ & 55 & 5.4 & $4 \cdot 1,7 \cdot 0$ & \\
\hline Intervention† & 451 & 43.8 & $40 \cdot 7,46 \cdot 9$ & 197 & 19.4 & $17 \cdot 0,22 \cdot 0$ & \\
\hline \multicolumn{8}{|l|}{ Study design } \\
\hline Systematic review/meta-analysis $†$ & 4 & 0.4 & $0.1,0.9$ & 155 & $15 \cdot 3$ & $13 \cdot 1,17 \cdot 6$ & $<0.001 \ddagger, \dagger$ \\
\hline Non-systematic reviews $\dagger$ & 157 & $15 \cdot 2$ & $13 \cdot 1,17 \cdot 6$ & 321 & 31.6 & $28 \cdot 7,34.5$ & \\
\hline Randomised controlled trialł & 183 & $17 \cdot 8$ & $15 \cdot 5,20 \cdot 2$ & 133 & $13 \cdot 1$ & $11 \cdot 1,15 \cdot 3$ & \\
\hline Non-randomised trial $\dagger$ & 206 & $20 \cdot 0$ & $17 \cdot 6,22 \cdot 6$ & 12 & 1.2 & $0 \cdot 6,2 \cdot 1$ & \\
\hline Cohort† & 39 & 3.8 & $2 \cdot 7,5 \cdot 1$ & 146 & 14.4 & $12 \cdot 3,16 \cdot 7$ & \\
\hline Case controlt & 79 & $7 \cdot 7$ & $6 \cdot 1,9.5$ & 28 & 2.8 & $1.8,4.0$ & \\
\hline Case series $\dagger$ & 105 & $10 \cdot 2$ & $8 \cdot 4,12 \cdot 2$ & 33 & 3.2 & $2 \cdot 2,4 \cdot 5$ & \\
\hline Cross-sectional† & 233 & $22 \cdot 6$ & $19 \cdot 2,24 \cdot 3$ & 148 & $14 \cdot 6$ & $12 \cdot 5,16 \cdot 9$ & \\
\hline Decision/cost effectiveness & 1 & 0.1 & $0.02,0.5$ & 3 & 0.3 & $0.06,0.9$ & \\
\hline Qualitative/mixed methods & 0 & 0 & - & 10 & 1.0 & $0.5,1.8$ & \\
\hline Other study design & 23 & $2 \cdot 2$ & $1 \cdot 4,3 \cdot 3$ & 27 & 2.7 & $1 \cdot 8,3 \cdot 8$ & \\
\hline \multicolumn{8}{|l|}{ Translation phase } \\
\hline TO† & 844 & 81.9 & $79 \cdot 5,84 \cdot 2$ & 737 & $72 \cdot 5$ & $69 \cdot 7,75 \cdot 3$ & $<0.001 \ddagger, \dagger$ \\
\hline T1t & 147 & $14 \cdot 3$ & $12 \cdot 2,16 \cdot 6$ & 93 & $9 \cdot 2$ & $7 \cdot 5,11 \cdot 1$ & \\
\hline $\mathrm{T} 2 \dagger$ & 37 & $3 \cdot 6$ & $2.5,4.9$ & 160 & $15 \cdot 7$ & $13 \cdot 6,18 \cdot 1$ & \\
\hline T3† & 1 & $0 \cdot 1$ & $0.02,0.5$ & 19 & 1.9 & $1 \cdot 1,2 \cdot 9$ & \\
\hline $\mathrm{T} 4$ & 1 & 0.1 & $0.02,0.5$ & 7 & 0.7 & $0.3,1.4$ & \\
\hline \multicolumn{8}{|l|}{ IFDIT translation process of research } \\
\hline Basic researcht & 877 & $85 \cdot 2$ & $82 \cdot 8,87 \cdot 3$ & 740 & $72 \cdot 8$ & $70 \cdot 0,75 \cdot 5$ & $<0.001 \mp, \dagger$ \\
\hline Pre-clinical research $†$ & 117 & 11.4 & $9.5,13.5$ & 88 & 8.7 & $7 \cdot 0,10 \cdot 6$ & \\
\hline Clinical research $\dagger$ & 34 & $3 \cdot 3$ & $2 \cdot 3,4 \cdot 6$ & 167 & $16 \cdot 4$ & $14 \cdot 2,18 \cdot 9$ & \\
\hline Clinical implementation $†$ & 1 & 0.1 & $0.02,0.5$ & 16 & 1.6 & $0.9,2.5$ & \\
\hline Public health & 1 & 0.1 & $0.02,0.5$ & 5 & 0.5 & $0.2,1.1$ & \\
\hline
\end{tabular}

IFDIT, Integrative Framework of Dissemination, Implementation and Translation.

${ }^{*}$ Person's $\chi^{2}$ statistical test for difference across time unless otherwise indicated.

†Fisher's exact test.

łIndicates statistical significance $(P<0.05)$ based on $95 \% \mathrm{Cl}$. 
journals that remained the same between 1998 and 2018. This sensitivity analysis enabled us to assess the robustness of the results, and whether the inclusion of different journals impacted on overall findings.

\section{Results}

Overall, eighty-nine journals were indexed as Nutrition and Dietetics in Web of Science. The top eight journals were selected and 2161 articles were downloaded from these journals. One hundred fifteen articles that did not present new data (e.g., editorials ( $n$ 26), letters to the editor ( $n 2$ ), post-publication correction ( $n$ 2), professional development material ( $n$ 8) and conference abstracts/symposia $(n$ 77)) were excluded at title/abstract screening. A total of 2046 studies were included in the following data extraction ( $n 1030$ from 1998 journals, $n 1016$ from 2018 journals) (see Fig. 1). The journal, scope, impact factor, volume and issue numbers for 1998 and 2018 are presented in Table 1. Four of the eight journals remained the same across both time points (Progress in Lipid Research, Annual Review of Nutrition, American Journal of Clinical Nutrition and Critical Reviews in Food Science and Nutrition).

\section{Overall}

Study type and study design

The majority of research was classed as descriptive in both 1998 and 2018; however, there was a significant decline in intervention studies between 1998 and 2018 (43.8\% in 1998 and $19.4 \%$ in 2018) and significant increases in descriptive research (51.4\% in 1998 and $75.2 \%$ in 2018). In 1998, the most common study designs were crosssectional studies $(22.6 \%)$, followed by non-randomised trials (20.0\%) and randomised controlled trials (17.8\%). In 2018, the most common study design was non-systematic reviews (31.6\%), followed by systematic reviews and metaanalyses (15.3\%) and cross-sectional studies (14.6\%). All other study designs accounted for $<10 \%$ of publications. Shifts for all study characteristics were significantly different across time $(P<0.001)$.

Across the two time points, there were changes in the proportion of systematic reviews (increase from $0.4 \%$ in 1998 to $15.3 \%$ in 2018), non-systematic reviews (increase from $15.2 \%$ in 1998 to $31.6 \%$ in 2018), randomised controlled trials (decrease from $17.8 \%$ in 1998 to $13.1 \%$ in 2018), non-randomised trials (decrease from $20.0 \%$ in 1998 to $1.2 \%$ in 2018), cohort (increase from $3.8 \%$ in 1998 to $14.4 \%$ in 2018) and cross-sectional studies (decrease from $22.6 \%$ in 1998 to $14.6 \%$ in 2018) (see Table 2).

Broad nutrition focus and specific content area When assessing by journals that had a broad nutrition focus, we found similar trends to the overall sample
( $n 633$ in 1998 and $n 997$ in 2018). There were similar declines in intervention research from $45.7 \%$ in 1998 to $19.8 \%$ in 2018 and increases in descriptive research ( $48.3 \%$ in 1998 to $74.7 \%$ in 2018), as well as similar increases in systematic reviews and cohort studies. However, among journals that focused on a specific content area (i.e., lipids, obesity), the proportion of descriptive (56.4\% in 1998 , $58.4 \%$ in 2018) and intervention (40.8\% in 2018, 38.9\% in 2018) research, as well as study designs remained largely unchanged across time (see Table 3).

\section{Included a public bealth focus and did not include a public bealth focus}

For journals that included a public health focus ( $n 18$ in 1998, $n 270$ in 2018), there were large increases in intervention research (from $0 \%$ in 1998 to $17 \cdot 8 \%$ in 2018) in contrast to the overall sample and across all study designs. For journals that did not include a public health focus ( $n 1012$ in 1998, $n 746$ in 2018), the observed changes were similar to the overall sample with decreases in intervention research ( $44.6 \%$ in 1998 to $20 \%$ in 2018) and increases in descriptive research (50.6\% in 1998 to $74.1 \%$ in 2018), and similar changes in types of study design (see Table 3 ).

\section{Translation phase}

Overall

For both years, the majority of research was in the T0 phase and consisted of basic research. There was a significant difference in percentage of $\mathrm{T} 0$-focused publications ( $81.9 \%$ in $1998 v .72 .5 \%$ in 2018) and basic research (85.2\% in $1998 v$. $72.8 \%$ in 2018). Additionally, there was a higher proportion of research focused on clinical research in 2018 (16.4\% $v$. $3.3 \%$ in 1998) (Table 2). A total of twenty-eight studies were classed as T3 and T4 (two in 1998 and twenty-six in 2018). The specific areas of examination for T3/T4 studies in 2018 were dissemination ( $n 9)$, implementation ( $n$ 17), adaptation of guidelines ( $n$ 1), sustainability $(n 2)$ and scaling-up ( $n 7)$.

\section{Broad nutrition focus and targeted focus}

When assessing by journals that had a broad nutrition focus, we found similar trends to the overall sample ( $n$ 633 in 1998 and $n 997$ in 2018). There were similar declines in T0-focused research from $86.6 \%$ in 1998 to $72.0 \%$ in 2018 and basic science research $(88.5 \%$ in 1998 to $72.3 \%$ in 2018), as well as increases in clinical research. Similarly, there was increase in T3/4 research from zero in 1998 to $2.6 \%$ in 2018. Among journals that focused on a particular nutrition area (i.e., lipids, obesity), there were no changes in translation phase and translation process of research between 1998 and 2018.

\section{Included a public health focus and did not include a public bealth focus}

For journals that included a public health focus ( $n 18$ in 1998, $n 270$ in 2018), there were large decreases in T0 
Table 3 Study type, design and translational research phase for studies published in the top eight ranked Nutrition and Dietetics journals in 1998 and 2018 by subgroups

\begin{tabular}{|c|c|c|c|c|c|c|c|c|}
\hline \multirow[b]{2}{*}{ Subgroup } & \multirow[b]{2}{*}{ Study type } & \multicolumn{3}{|c|}{$1998(n$ 1030) } & \multicolumn{3}{|c|}{$2018(n$ 1016) } & \multirow[b]{2}{*}{$P^{\star}$} \\
\hline & & $n$ & $\begin{array}{l}\text { Proportion } \\
\quad(\%)\end{array}$ & $95 \% \mathrm{Cl}$ & $n$ & $\begin{array}{l}\text { Proportion } \\
\quad(\%)\end{array}$ & $95 \% \mathrm{Cl}$ & \\
\hline \multirow{3}{*}{$\begin{array}{l}\text { Broad nutrition } \\
\text { focus }\end{array}$} & Descriptive & 306 & $48 \cdot 3$ & $44 \cdot 4,52,3$ & 745 & $74 \cdot 7$ & $71.9,77.4$ & \multirow{3}{*}{$<0.001$} \\
\hline & Intervention & 289 & $45 \cdot 7$ & $41 \cdot 7,49 \cdot 6$ & 197 & 19.8 & $17 \cdot 3,22 \cdot 4$ & \\
\hline & Measurement & 38 & $6 \cdot 0$ & $4 \cdot 3,8 \cdot 1$ & 55 & 5.5 & $4 \cdot 2,7 \cdot 1$ & \\
\hline \multirow[t]{3}{*}{ Targeted topics } & Descriptive & 224 & $56 \cdot 4$ & $51 \cdot 4,61.4$ & 19 & 100 & - & \multirow[t]{3}{*}{$<0.001 \dagger, \ddagger$} \\
\hline & Intervention & 162 & $40 \cdot 8$ & $35 \cdot 9,45 \cdot 8$ & 0 & 0 & - & \\
\hline & Measurement & 11 & $2 \cdot 8$ & $1.4,4.9$ & 0 & 0 & - & \\
\hline \multirow{3}{*}{$\begin{array}{l}\text { Public Health } \\
\text { inclusive focus }\end{array}$} & Descriptive & 18 & 100 & - & 211 & $78 \cdot 1$ & $72 \cdot 7,83 \cdot 9$ & \multirow[t]{3}{*}{$0.088 \dagger, \ddagger$} \\
\hline & Intervention & 0 & 0 & - & 48 & $17 \cdot 8$ & $13 \cdot 4,22.9$ & \\
\hline & Measurement & 0 & 0 & - & 11 & 4.1 & $2 \cdot 1,7 \cdot 2$ & \\
\hline \multirow{4}{*}{$\begin{array}{l}\text { Non-public health } \\
\text { inclusive focus }\end{array}$} & Descriptive & 512 & $50 \cdot 6$ & $47 \cdot 5,53 \cdot 7$ & 553 & $74 \cdot 1$ & $70 \cdot 8,77 \cdot 2$ & \multirow[t]{3}{*}{$<0.001 \uparrow, \ddagger$} \\
\hline & Intervention & 451 & 44.6 & $41 \cdot 5,47 \cdot 7$ & 149 & $20 \cdot 0$ & $17 \cdot 2,23 \cdot 0$ & \\
\hline & Measurement & 49 & $4 \cdot 8$ & $3 \cdot 6,6 \cdot 4$ & 44 & $5 \cdot 9$ & $4 \cdot 3,7 \cdot 8$ & \\
\hline & Study design & $n$ & $\begin{array}{l}\text { Proportion } \\
\text { (\%) }\end{array}$ & & $n$ & $\begin{array}{l}\text { Proportion } \\
\text { (\%) }\end{array}$ & & $P$ value \\
\hline \multirow{11}{*}{$\begin{array}{l}\text { Broad nutrition } \\
\text { focus }\end{array}$} & Case control & 39 & $6 \cdot 2$ & $4 \cdot 4,8 \cdot 3$ & 28 & $2 \cdot 8$ & $1 \cdot 8,4 \cdot 0$ & $<0.001 \dagger, \S$ \\
\hline & Case series & 70 & $11 \cdot 1$ & $8 \cdot 7,13 \cdot 8$ & 33 & $3 \cdot 3$ & $2 \cdot 3,4 \cdot 6$ & \\
\hline & Cohort & 15 & $2 \cdot 4$ & $1 \cdot 3,3 \cdot 9$ & 146 & $14 \cdot 6$ & $12 \cdot 5,17 \cdot 0$ & \\
\hline & Cross-sectional & 98 & $15 \cdot 5$ & $12 \cdot 8,18 \cdot 5$ & 148 & $14 \cdot 8$ & $12 \cdot 7,17 \cdot 2$ & \\
\hline & Non-randomised trial & 120 & $19 \cdot 0$ & $16 \cdot 0,22 \cdot 2$ & 12 & 1.2 & $0.06,2 \cdot 1$ & \\
\hline & Non-systematic review & 128 & $20 \cdot 2$ & $17 \cdot 2,23 \cdot 6$ & 302 & $30 \cdot 3$ & $27 \cdot 4,33 \cdot 3$ & \\
\hline & Other & 22 & 3.5 & $2 \cdot 2,5 \cdot 2$ & 27 & $2 \cdot 7$ & $1.7,3.9$ & \\
\hline & Randomised controlled trial & 139 & $22 \cdot 0$ & $18 \cdot 8,25 \cdot 4$ & 133 & $13 \cdot 3$ & $11 \cdot 2,15 \cdot 6$ & \\
\hline & Systematic review/meta-analysis & 2 & 0.3 & $0.04,1.1$ & 155 & $15 \cdot 5$ & $13 \cdot 2,17.9$ & \\
\hline & Decision and cost effectiveness & $\overline{0}$ & 0 & - & 3 & 0.3 & $0.06,0.9$ & \\
\hline & Qualitative/mixed methods & 0 & 0 & - & 10 & 1.0 & $0.5,1.9$ & \\
\hline Targeted topics & Case control & 40 & $10 \cdot 1$ & $7 \cdot 3,13 \cdot 5$ & 0 & 0 & - & $<0.001 \dagger, \S$ \\
\hline & Case series & 35 & $8 \cdot 8$ & $6 \cdot 2,12 \cdot 0$ & 0 & 0 & - & \\
\hline & Cohort & 24 & $6 \cdot 0$ & $3.9,8.9$ & 0 & 0 & - & \\
\hline & Cross-sectional & 135 & $34 \cdot 0$ & $29 \cdot 4,38 \cdot 9$ & 0 & 0 & - & \\
\hline & $\begin{array}{l}\text { Decision and cost } \\
\text { effectiveness }\end{array}$ & 1 & 0.3 & $0.006,1 \cdot 4$ & 0 & 0 & - & \\
\hline & Non-randomised trial & 86 & $21 \cdot 7$ & $17 \cdot 7,26 \cdot 0$ & 0 & 0 & - & \\
\hline & Non-systematic review & 29 & $7 \cdot 3$ & $4 \cdot 9,10 \cdot 3$ & 19 & 100 & - & \\
\hline & Other & 1 & 0.3 & $0.006,1.4$ & 0 & 0 & - & \\
\hline & Randomised controlled trial & 44 & $11 \cdot 1$ & $8 \cdot 2,14.6$ & 0 & 0 & - & \\
\hline & Systematic review/meta-analysis & 2 & 0.5 & $0.06,1.8$ & 0 & 0 & - & \\
\hline Public Health & Non-systematic review & 18 & 100 & - & 96 & $35 \cdot 6$ & $29 \cdot 8,41 \cdot 6$ & $0.001 \dagger, \ddagger$ \\
\hline inclusive focus & Case control & 0 & 0 & - & 1 & 0.4 & $0 \cdot 009,2 \cdot 1$ & \\
\hline & Case series & 0 & 0 & - & 5 & 1.9 & $0.6,4.3$ & \\
\hline & Cohort & 0 & 0 & - & 16 & $5 \cdot 9$ & $3 \cdot 4,9.5$ & \\
\hline & Cross-sectional & 0 & 0 & - & 45 & $16 \cdot 7$ & $12 \cdot 4,21 \cdot 7$ & \\
\hline & $\begin{array}{l}\text { Decision and cost } \\
\text { effectiveness }\end{array}$ & 0 & 0 & - & 1 & 0.4 & $0.009,2 \cdot 1$ & \\
\hline & Non-randomised trial & 0 & 0 & - & 2 & 0.7 & $0.09,2.7$ & \\
\hline & Other & 0 & 0 & - & 10 & 3.7 & $1 \cdot 8,6 \cdot 7$ & \\
\hline & Qualitative/mixed methods & 0 & 0 & - & 1 & 0.4 & $0.009,2.1$ & \\
\hline & Randomised controlled trial & 0 & 0 & - & 28 & $10 \cdot 4$ & $7 \cdot 0,14 \cdot 6$ & \\
\hline & Systematic review/meta-analysis & 0 & 0 & - & 65 & $24 \cdot 1$ & $19 \cdot 1,29 \cdot 6$ & \\
\hline Non-public health & Case control & 79 & $7 \cdot 8$ & $6 \cdot 2,9 \cdot 6$ & 27 & 3.6 & $2 \cdot 4,5 \cdot 2$ & $<0.001 \dagger, \S$ \\
\hline inclusive focus & Case series & 105 & $10 \cdot 4$ & $8 \cdot 6,12 \cdot 4$ & 28 & $3 \cdot 8$ & $2 \cdot 5,5 \cdot 4$ & \\
\hline & Cohort & 39 & 3.9 & $2 \cdot 8,5 \cdot 2$ & 130 & $17 \cdot 4$ & $14 \cdot 8,20 \cdot 3$ & \\
\hline & Cross-sectional & 233 & $23 \cdot 0$ & $20 \cdot 5,25 \cdot 7$ & 103 & $13 \cdot 8$ & $11.4,16.5$ & \\
\hline & $\begin{array}{l}\text { Decision and cost } \\
\text { effectiveness }\end{array}$ & 1 & 0.1 & $0.003,0.5$ & 2 & 0.3 & $0.03,1.0$ & \\
\hline & Non-randomised trial & 206 & $20 \cdot 4$ & $17 \cdot 9,23 \cdot 0$ & 10 & $1 \cdot 3$ & $0.6,2.5$ & \\
\hline & Non-systematic review & 139 & 13.7 & $11 \cdot 7,16 \cdot 0$ & 225 & $30 \cdot 2$ & $26 \cdot 9,33 \cdot 6$ & \\
\hline & Other & 23 & $2 \cdot 3$ & $1.4,3.4$ & 17 & $2 \cdot 3$ & $1 \cdot 3,3 \cdot 6$ & \\
\hline & Randomised controlled trial & 183 & $18 \cdot 1$ & $15 \cdot 8,20 \cdot 6$ & 105 & $14 \cdot 1$ & $11 \cdot 7,16 \cdot 8$ & \\
\hline & Systematic review/meta-analysis & 4 & 0.4 & $0.1,1.0$ & 90 & $12 \cdot 1$ & $9.8,14.6$ & \\
\hline & Qualitative/mixed methods & 0 & 0 & - & 9 & $1 \cdot 2$ & $0.5,2 \cdot 3$ & \\
\hline & Translation phase & $n$ & $\begin{array}{l}\text { Proportion } \\
\text { (\%) }\end{array}$ & & $n$ & $\begin{array}{l}\text { Proportion } \\
\quad(\%)\end{array}$ & & $P$ value \\
\hline Broad nutrition & T0 & 548 & $86 \cdot 6$ & $83 \cdot 7,89 \cdot 1$ & 718 & $72 \cdot 0$ & $69 \cdot 1,74 \cdot 8$ & $<0.001 \dagger$ \\
\hline focus & $\mathrm{T} 1$ & 58 & 9.2 & $7 \cdot 0,11 \cdot 7$ & 93 & $9 \cdot 3$ & $7 \cdot 6,11 \cdot 3$ & \\
\hline
\end{tabular}


Table 3 Continued

\begin{tabular}{|c|c|c|c|c|c|c|c|c|}
\hline \multirow[b]{2}{*}{ Subgroup } & \multirow[b]{2}{*}{ Study type } & \multicolumn{3}{|c|}{$1998(n 1030)$} & \multicolumn{3}{|c|}{$2018(n$ 1016) } & \multirow[b]{2}{*}{$P^{*}$} \\
\hline & & $n$ & $\begin{array}{l}\text { Proportion } \\
(\%)\end{array}$ & $95 \% \mathrm{Cl}$ & $n$ & $\begin{array}{l}\text { Proportion } \\
\text { (\%) }\end{array}$ & $95 \% \mathrm{Cl}$ & \\
\hline & T2 & 27 & 4.3 & $2 \cdot 8,6 \cdot 1$ & 160 & $16 \cdot 0$ & $13 \cdot 8,18 \cdot 5$ & \\
\hline & T3 & 0 & 0 & - & 19 & 1.9 & $1 \cdot 2,3 \cdot 0$ & \\
\hline & $\mathrm{T} 4$ & 0 & 0 & - & 7 & 0.7 & $0.3,1.4$ & \\
\hline \multirow[t]{5}{*}{ Targeted topics } & T0 & 296 & $74 \cdot 6$ & $70 \cdot 0,78 \cdot 8$ & 19 & 100 & - & $0.081 \dagger, \ddagger$ \\
\hline & T1 & 89 & $22 \cdot 4$ & $18 \cdot 4,26 \cdot 8$ & 0 & 0 & - & \\
\hline & $\mathrm{T} 2$ & 10 & $2 \cdot 5$ & $1 \cdot 2,4 \cdot 6$ & 0 & 0 & - & \\
\hline & T3 & 1 & 0.3 & $0.006,1.4$ & 0 & 0 & - & \\
\hline & $\mathrm{T} 4$ & 1 & 0.3 & $0.006,1.4$ & 0 & 0 & - & \\
\hline Public health & T0 & 18 & 100 & - & 188 & $69 \cdot 6$ & $63 \cdot 8,75 \cdot 1$ & 0.090†,‡ \\
\hline \multirow{4}{*}{ inclusive focus } & T1 & 0 & 0 & - & 22 & $8 \cdot 1$ & $5 \cdot 2,12 \cdot 1$ & \\
\hline & T2 & 0 & 0 & - & 54 & $20 \cdot 0$ & $15 \cdot 4,25 \cdot 3$ & \\
\hline & T3 & 0 & 0 & - & 5 & 1.9 & $0 \cdot 6,4 \cdot 3$ & \\
\hline & $\mathrm{T} 4$ & 0 & 0 & - & 1 & 0.4 & $0.009,2.0$ & \\
\hline \multirow{6}{*}{$\begin{array}{l}\text { Non-public health } \\
\text { inclusive focus }\end{array}$} & T0 & 826 & $81 \cdot 6$ & $86 \cdot 4,90 \cdot 4$ & 549 & 73.6 & $70 \cdot 3,76 \cdot 7$ & $<0.001 \dagger$ \\
\hline & T1 & 147 & 14.5 & $12 \cdot 4,16 \cdot 8$ & 71 & 9.5 & $7.5,11.9$ & \\
\hline & T2 & 37 & 3.7 & $2 \cdot 6,5 \cdot 0$ & 106 & $14 \cdot 2$ & $11 \cdot 8,16 \cdot 9$ & \\
\hline & T3 & 1 & $0 \cdot 1$ & $0.003,0.5$ & 14 & $1 \cdot 9$ & $1 \cdot 0,3 \cdot 1$ & \\
\hline & $\mathrm{T} 4$ & 1 & $0 \cdot 1$ & $0.003,0.5$ & 6 & 0.8 & $0.3,1 \cdot 7$ & \\
\hline & $\begin{array}{l}\text { IFDIT translation process of } \\
\text { research }\end{array}$ & $n$ & $\begin{array}{l}\text { Proportion } \\
\text { (\%) }\end{array}$ & & $n$ & $\begin{array}{l}\text { Proportion } \\
\text { (\%) }\end{array}$ & & $P$ value \\
\hline \multirow{5}{*}{$\begin{array}{l}\text { Broad nutrition } \\
\text { focus }\end{array}$} & Basic research & 560 & 88.5 & $85 \cdot 7,90 \cdot 9$ & 721 & $72 \cdot 3$ & $69 \cdot 4,75 \cdot 1$ & $<0.001 \dagger$, \\
\hline & Pre-clinical research & 49 & $7 \cdot 7$ & $5 \cdot 8,10 \cdot 1$ & 88 & $8 \cdot 8$ & $7 \cdot 1,10 \cdot 8$ & \\
\hline & Clinical research & 0 & 0 & - & 1 & $0 \cdot 1$ & $0.003,0.6$ & \\
\hline & Clinical implementation & 0 & 0 & - & 16 & 1.6 & $0.9,2 \cdot 6$ & \\
\hline & Public health & 0 & 0 & - & 5 & 0.5 & $0 \cdot 2,1 \cdot 2$ & \\
\hline \multirow[t]{5}{*}{ Targeted topics } & Basic research & 317 & $79 \cdot 8$ & $75 \cdot 6,83 \cdot 7$ & 19 & 100 & - & $0.213 \dagger, \ddagger$ \\
\hline & Pre-clinical research & 68 & $17 \cdot 1$ & $13 \cdot 6,21 \cdot 2$ & 0 & 0 & - & \\
\hline & Clinical research & 10 & 2.5 & $1 \cdot 2,4 \cdot 6$ & 0 & 0 & - & \\
\hline & Clinical implementation & 1 & 0.3 & $0.006,1.4$ & 0 & 0 & - & \\
\hline & Public health & 1 & 0.3 & $0.006,1.4$ & 0 & 0 & - & \\
\hline & Basic research & 18 & 100 & - & 191 & $70 \cdot 7$ & $64 \cdot 9,76 \cdot 1$ & $0.129 \dagger, \ddagger$ \\
\hline \multirow{5}{*}{ inclusive focus } & Pre-clinical research & 0 & 0 & - & 19 & $7 \cdot 0$ & $4 \cdot 3,10 \cdot 8$ & \\
\hline & Public health & 0 & 0 & - & 2 & 0.7 & $0.09,2.7$ & \\
\hline & Clinical research & 0 & 0 & - & 1 & 0.4 & $0.009,2.0$ & \\
\hline & Clinical research & 0 & 0 & - & 55 & $20 \cdot 4$ & $15 \cdot 7,25 \cdot 7$ & \\
\hline & Public health & 0 & 0 & - & 2 & 0.7 & $0 \cdot 09,2 \cdot 7$ & \\
\hline & Basic research & 859 & 84.9 & $82 \cdot 5,87 \cdot 0$ & 549 & $73 \cdot 6$ & $70 \cdot 3,76 \cdot 7$ & $<0.001 \dagger$, \\
\hline \multirow{4}{*}{ inclusive focus } & Pre-clinical research & 117 & $11 \cdot 6$ & $9 \cdot 7,13 \cdot 7$ & 69 & $9 \cdot 2$ & $7 \cdot 3,11 \cdot 6$ & \\
\hline & Clinical implementation & 1 & 0.1 & $0.003,0.5$ & 14 & 1.9 & $1 \cdot 0,3 \cdot 1$ & \\
\hline & Clinical research & 34 & 3.4 & $2 \cdot 3,4 \cdot 7$ & 111 & 14.9 & $12 \cdot 4,17 \cdot 6$ & \\
\hline & Public health & 1 & 0.1 & $0.003,0.5$ & 3 & 0.4 & $0.08,1 \cdot 2$ & \\
\hline
\end{tabular}

IFDIT, Integrative Framework of Dissemination, Implementation and Translation. *Person's $\chi^{2}$ statistical test for difference across time unless otherwise indicated. †Indicates statistical significance $(P<0.05)$ based on $95 \% \mathrm{Cl}$.

‡Fisher's exact test.

$\S$ Fisher's exact test with Monte Carlo simulated $P$-value.

research (100\% in 1998 to $69.6 \%$ in 2018) and basic science research accompanied by small increases in the proportion of T3/T4 research (from $0 \%$ in 1998 to $2.3 \%$ studies overall in 2018). Notably, only $0.7 \%$ of published research across both time points was public health focused. For journals that did not include a public health focus ( $n$ 1012 in 1998, $n 746$ in 2018), the observed changes were similar to the overall sample with decreases in T0 research ( $81.6 \%$ in 1998 to $73.6 \%$ in 2018) and increases in T3/T4 research $(0.2 \%$ in 1998 to $2.7 \%$ in 2018), and increases in clinical research designs $(3.4 \%$ in 1998 to $14.9 \%$ in 2018).

\section{Sensitivity analysis (only limited to journals that remained the same across both time points)}

The analysis was repeated with the four journals that remained the same across both time points. For these journals, we found no changes in study type with similar proportion of descriptive, intervention and measurement research across time $(P=0 \cdot 178)$. We found similar increases in cohort study ( $4.5 \%$ in 1998 to $11.2 \%$ in 2018 ) and systematic reviews (from $0.4 \%$ in 1998 to $11.2 \%$ in 2018) to the broader sample. Notably, there was no T3/T4 research published in these journals across both time points (see online Supplementary material, Supplemental Table S6). 


\section{Discussion}

The current study sought to provide an overview of the changes in types of research published in highly cited Nutrition and Dietetic journals over a 20 -year period. The period of time which it takes research to be translated from bench to bedside is commonly cited as 17 years ${ }^{(30)}$. In covering this period of time, it was hypothesised that there would be an increase in intervention and translational and implementation study designs. Consistent with previous studies $^{(8,16,17)}$, the majority of published research in these journals were descriptive across both time points. However, there was a significantly higher percentage of intervention research in 1998 (43.8\%) compared with 2018 (19.4\%). Such a decline was unexpected as other bibliographic studies examining physical activity and smoking research have documented either an increase or no change in percentage of intervention studies published ${ }^{(8,16)}$. It is possible that many of the interest areas in Nutrition and Dietetics research are emerging and may require epidemiological examination prior to undertaking clinical trials.

The percentage of published reviews accounted for almost half of all publications in 2018. As findings from reviews are more highly cited $^{(17)}$, this is likely reflective of the sampling frame, which included the top-cited journals. The predominance of non-systematic reviews in 2018, however, is surprising. Although both types of reviews seek to provide an overview of the literature, systematic reviews may provide less biased answers to policy and practice questions as they are typically accompanied with pre-registration or detailed protocols to reduce selective reporting of the literature. However, they are also typically more resource intensive to undertake ${ }^{(31)}$ which may have accounted for the predominance of non-systematic reviews.

Understanding the spread of published literature as it relates to the translational phases (T0-T4) helps us grasp priority publication areas for top-cited journals. The balance of $\mathrm{T0}$ and basic research against clinical research publications was slightly shifted in 2018 , with a small decrease in the former and small increase in the latter. Despite this shift, T3/T4 research accounted for $<3 \%$ of all audited publications and the amount of intervention research was reduced by over half to $<20 \%$ in 2018 . Although dissemination and implementation research (T3/T4 research) and cost-effectiveness research are particularly useful for informing policy and practice, they typically require greater time, resources and are more complex relative to other research. While researchers recognise the need and importance for this type of research, there are significant time and resources needed to develop effective partnerships with policy makers, stakeholders and end-users to undertake this work, and the current model of incentivising academic publication does not reward undertaking such research ${ }^{(32)}$. Changes to funding schemes such as that already undertaken in the $\mathrm{USA}^{(33)}$ and Australia ${ }^{(34)}$ (e.g., special calls for funding of rigorous intervention research in priority health areas, funding support to develop partnerships between researchers and practitioners or policy makers) may assist in better aligning research output with research use and impact into the future. Further, while many highly ranked journals dedicated to publishing reviews in nutrition exist, there are none dedicated to publishing T3/T4 nutrition-related research. This makes it challenging for researchers and practitioners in the field to identify such research, and in turn, reduces the citation of such manuscripts.

The scope of a journal does appear to impact the types of research published over time. In our subgroup analysis, we found that the types of research published remained largely similar as the overall sample for journals with a broad nutrition focus, those without an explicit public health focus and the four journals that were consistent over time. Journals with a targeted focus area (i.e., focused on lipids, obesity specifically) showed consistency for the types and translation stages of publications over time, while public health-focused journals showed large decreases in descriptive and T0 research accompanied by increased intervention and $\mathrm{T} 3 / \mathrm{T} 4$ research. This suggests that the study type differences observed are largely due to the inclusion of broader nutrition focus journals and those without a public health focus. Notably, there was an absence of $\mathrm{T} 3 / \mathrm{T} 4$ publications at both time points in the four consistent top-cited journals and points to a major barrier for publishing implementation research in journals where it could have real and wide-reaching impact on academic inquiry and practice.

\section{Limitations}

The findings of the current study need to be interpreted in the context of the study design. Firstly, the included studies were sampled from just a fraction of all Nutrition and Dietetics journals (eight out of eighty-seven); thus, it is unlikely that these findings represent all published Nutrition and Dietetic research. Furthermore, the top eight ranked journals differed between 1998 and 2018, with only four of them being the same at both time points. Our sensitivity analysis found that there were no changes in the study designs and translation phase of published manuscripts for these journals, suggesting that any changes across trend were accounted for by the inclusion of the four different journals in 2018. The sampling frame focused on the top ranking and most cited Nutrition and Dietetics journals. It is therefore likely that data from more specialist journals (e.g., Implementation Science, Translational Behavioural Medicine) or more public health-focused journals (e.g., Public Health Nutrition, Journal of Nutrition Education and Behaviour and Journal of Academic Nutrition and Dietetics), which may publish a higher volume of translational Nutrition and Dietetics research, would differ from the journals described here. Indeed, our additional 
analysis suggests that the scope of journals is likely to have influenced the type of published research.

\section{Conclusions}

Over the 20-year period from 1998 to 2018, the study design and translation phase of publications changed across top-cited nutrition and dietetic journals as did the actual journals that made up the top-cited list. While this change was expected, the direction of change was somewhat surprising. A notable shift has occurred towards publishing reviews and clinical studies, with less intervention and basic sciences research in these journals, which is potentially due to editorial direction in nutrition journals with a broader focus. Despite expert consensus that research should ideally progress into dissemination and implementation research over time, we found only a small number of T3/T4 studies published in 2018. Encouragingly, publishing in the field of Nutrition and Dietetics is slowly moving towards translation-type studies with small significant changes over time. Further increases however are needed as improvements in dietary outcomes at a population level rely on the development of clinically effective research to be implemented and disseminated at a population level.

\section{Acknowledgements}

Acknowledgements: The authors wish to thank Li Kheng Chai for support with data extraction. Financial support: This project was funded by internal research funds provided to S.L.Y. by the Faculty of Health, University of Newcastle. Hunter New England Population Health, the University of Newcastle and Hunter Medical Research Institute provided infrastructure support. S.L.Y. is a postdoctoral research fellow funded by an Australian Research Council Discovery Early Career Researcher Award (DE170100382). Conflict of interest: None. Authorship: S.L.Y. conceived the study. S.L.Y., J.J., T.S., R.T., R.B. and R.S. contributed to the design of the project. S.L.Y., J.J., C.B., N.P. and A.B. conducted the data extraction. J.J. conducted the statistical analysis. S.L.Y. and R.S. developed the manuscript with critical editorial support from J.J., T.S., R.T., R.B. and C.B. All authors read and approved the final version of this manuscript. Ethics of buman subject participation: Not applicable.

\section{Supplementary material}

For supplementary material accompanying this paper visit https://doi.org/10.1017/S1368980021000136

\section{References}

1. Afshin A, Sur PJ, Fay KA et al. (2019) Health effects of dietary risks in 195 countries, 1990-2017: a systematic analysis for the Global Burden of Disease Study 2017. Lancet 393, 1958-1972.

2. Mathers C, Stevens G \& Mascarenhas M (2009) Global Health Risks: Mortality and Burden of Disease Attributable to Selected Major Risks. Geneva: World Health Organization.

3. Ezzati M \& Riboli E (2013) Behavioral and dietary risk factors for noncommunicable diseases. N Engl J Med 369, 954-964.

4. Traill WB (2012) Economic perspectives on nutrition policy evaluation. J Agric Econ 63, 505-527.

5. Nutbeam D (1996) Achieving 'best practice' in health promotion: improving the fit between research and practice. Health Educ Res 11, 317-326.

6. Nutbeam D \& Bauman AE (2006) Evaluation in a Nutshell: A Practical Guide to the Evaluation of Health Promotion Programs. New York: McGraw-Hill.

7. Flay BR (1986) Efficacy and effectiveness trials (and other phases of research) in the development of health promotion programs. Prev Med 15, 451-474.

8. Milat AJ, Bauman AE, Redman S et al. (2011) Public health research outputs from efficacy to dissemination: a bibliometric analysis. BMC Public Health 11, 934.

9. National Center for Advancing Translational Sciences (2020) Translational science Spectrum 2020. https://ncats.nih.gov/ translation/spectrum (accessed June 2020).

10. Liverman CT, Schultz AM, Terry SF et al. (2013) The CTSA Program at NIH: Opportunities for Advancing Clinical and Translational Research. Washington DC: National Academies Press.

11. Glasgow RE, Vinson C, Chambers D et al. (2012) National Institutes of Health approaches to dissemination and implementation science: current and future directions. Am J Public Health 102, 1274-1281.

12. Grimshaw JM, Eccles MP, Lavis JN et al. (2012) Knowledge translation of research findings. Implement Sci 7, 50 .

13. Glanzel W (2005) Bibliometrics as a research field: a course on theory and application of bibliometric indicators. Landolt-Börnstein - Group III Cond Mat 81(02), 1-2.

14. Clifford A \& Shakeshaft A (2017) A bibliometric review of drug and alcohol research focused on Indigenous peoples of Australia, New Zealand, Canada and the United States. Drug Alcohol Rev 36, 509-522.

15. Wingerter DG, Azevedo UND, Marcaccini AM et al. (2018) Scientific production on falls and deaths among elderly persons: a bibliometric analysis. Rev Bras Geriatr Gerontol 21, 320-329.

16. Metse AP, Wiggers JH, Wye PM et al. (2017) Smoking and mental illness: a bibliometric analysis of research output over time. Nicotine Tob Res 19, 24-31.

17. Wolfenden L, Milat AJ, Lecathelinais C et al. (2016) What is generated and what is used: a description of public health research output and citation. Eur I Public Health 26, 523-525.

18. Ellegaard O \& Wallin JA (2015) The bibliometric analysis of scholarly production: how great is the impact? Scientometrics 105, 1809-1831.

19. Clarivate (2019) InCites journal citation reports. https:// clarivate.com/webofsciencegroup/wp-content/uploads/ sites/2/dlm_uploads/2019/08/JCR_Full_Journal_list140619.pdf (accessed February 2021).

20. Sharma M, Sarin A, Gupta P et al. (2014) Journal impact factor: its use, significance and limitations. World $\mathrm{J} \mathrm{Nucl}$ Med 13, 146. 
21. Sanson-Fisher RW, Campbell EM, Htun AT et al. (2008) We are what we do: research outputs of public health. Am J Prev Med 35, 380-385.

22. Shadish WR, Cook TD \& Campbell DT (2002) Experimental and Quasi-Experimental Designs for Generalized Causal Inference. Boston: Houghton Mifflin.

23. National Health Medical Research Council (2009) NHMRC Additional Levels of Evidence and Grades for Recommendations for Developers of Guidelines. Canberra: NHMRC.

24. Mercer SL, DeVinney BJ, Fine LJ et al. (2007) Study designs for effectiveness and translation research: identifying tradeoffs. Am J Prev Med 33, 139-154.e132.

25. Leppin AL, Mahoney JE, Stevens KR et al. (2020) Situating dissemination and implementation sciences within and across the translational research spectrum. J Clin Transl Sci $\mathbf{4}, 152-158$.

26. US Department of Health and Human Services \& National Institute of Health (2020) Implementation Science at a glance: a guide for cancer control practitioners. https:// cancercontrol.cancer.gov/IS/docs/NCI-ISaaG-Workbook. pdf (accessed June 2020).

27. Stirman SW, Baumann AA \& Miller CJ (2019) The FRAME: an expanded framework for reporting adaptations and modifications to evidence-based interventions. Implement Sci 14, $1-10$.
28. Scheirer MA \& Dearing JW (2011) An agenda for research on the sustainability of public health programs. Am J Public Health 101, 2059-2067.

29. Milat AJ, Newson R, King L et al. (2016) A guide to scaling up population health interventions. Public Health Res Pract 26, e2611604

30. Morris ZS, Wooding S \& Grant J (2011) The answer is 17 years, what is the question: understanding time lags in translational research. J R Soc Med 104, 510-520.

31. Borah R, Brown AW, Capers PL et al. (2017) Analysis of the time and workers needed to conduct systematic reviews of medical interventions using data from the PROSPERO registry. BMJ Open 7, e012545.

32. Knoepke CE, Ingle MP, Matlock DD et al. (2019) Dissemination and stakeholder engagement practices among dissemination \& implementation scientists: results from an online survey. PLoS One 14, e0216971.

33. National Institute of Environmental Health Sciences (2019) NIH Roadmap and Roadmap-affiliated Initiatives. https://www.niehs.nih.gov/funding/grants/announcements/ roadmap/index.cfm (accessed June 2020).

34. National Health and Medical Research Council (2020) Building a Healthy Australia: partnership Projects. https://www.nhmrc. gov.au/funding/find-funding/partnership-projects (accessed June 2020). 